\title{
Ion-track etched templates for the high density growth of nanowires of bismuth telluride and bismuth antimony telluride by electrodeposition
}

\author{
E. Koukharenko ${ }^{\mathrm{a}}$, N. M. White ${ }^{\mathrm{a}}, \mathrm{X} . \mathrm{Li}^{\mathrm{b}}$, and I. S. Nandhakumar ${ }^{\mathrm{b}}$ \\ ${ }^{a}$ School of Electronics and Computer Science, University of Southampton, Southampton, \\ SO17 1BJ, UK \\ ${ }^{\mathrm{b}}$ School of Chemistry, University of Southampton, Southampton, SO17 1BJ, UK
}

\begin{abstract}
We report the electrochemical growth of high density arrays of ntype $\mathrm{Bi}_{2} \mathrm{Te}_{3}$ and p-type $\mathrm{Bi}_{0.5} \mathrm{Sb}_{1.5} \mathrm{Te}_{3}$ nanowires into ion-track etched polyimide-based Kapton membranes with a density of $5 \mathrm{x}$ $10^{9}$ wires $/ \mathrm{cm}^{2}$. The average diameter of the nanowires is $80 \mathrm{~nm}$ with a length of $20 \mu \mathrm{m}$, which is comparable to the pore size and thickness of the employed Kapton foils. The electroplating parameters and microstructural properties are reported for the nanowires whilst thermoelectric properties have been investigated for thin films of $\mathrm{Bi}_{2} \mathrm{Te}_{3}$ and $\mathrm{Bi}_{0.5} \mathrm{Sb}_{1.5} \mathrm{Te}_{3}$.
\end{abstract}

\section{Introduction}

Current focus on energy sustainability and stricter legislation on the emission of $\mathrm{CO}_{2}$ has sparked a renewed interest in thermoelectric (TE) power harvesting technologies which can directly convert thermal waste heat into useful electricity. TE generators consist of highly doped p-n-semiconducting junctions electronically connected in series and thermally in parallel which can generate power by utilizing the Seebeck effect and the Peltier effect for cooling. Thermoelectric devices offer advantages over other energy harvesting techniques which include solid-state operation with no moving parts, zeroemission, silent operation, vast scalability and high reliability with no maintenance and long operating lifetimes (1). Despite these merits the use of TE generators has been vastly limited to niche applications due to their low efficiency and bulky size. The efficiency of a TE generator is related to so called figure of merit, $Z T$ (2):

$$
Z T=\frac{\sigma S^{2} T}{\kappa}
$$

where $\sigma$ is the electrical conductivity, $\mathrm{S}$ is the Seebeck coefficient, , $\mathrm{T}$ the absolute temperature and $\kappa$ is the thermal conductivity respectively. High efficiency TE materials therefore require a high $Z T$ value, which in turn requires a large $\sigma S^{2}$ and a low $\kappa$. The currently best performing TE materials in commercial TE devices are based on bulk alloys of bismuth telluride such as n-type $\mathrm{Bi}_{2} \mathrm{Te}_{3}$ and p-type $\mathrm{Bi}_{0.5} \mathrm{Sb}_{1.5} \mathrm{Te}_{3}$ for refrigeration and waste heat recovery up to $200^{\circ} \mathrm{C}$ and have shown maximum ZT values of about 1 (2). In heavily doped bulk semiconductors $\sigma$ and $\kappa$ are interlinked due to the WiedemannFranz law and cannot be varied independently which makes it difficult to increase ZT. Dresselhaus et al. (3) however calculated that low dimensional structures such as $1 \mathrm{D}$ 
nanowires and 2D quantum wells systems could dramatically increase $\mathrm{S}$ and hence ZT in $\mathrm{TE}$ materials to $\mathrm{ZT} \geq 10$. This is due to an enhancement in the density of states (DOS) near the Fermi level via quantum confinement and a reduced lattice thermal conductivity due to increased phonon surface scattering in nanoscale systems. Nanostructures therefore offer an exciting opportunity to engineer materials with enhanced ZTs as $\sigma$ and $\kappa$ can be decoupled via quantum confinement in low dimensional systems. For these reasons bismuth telluride alloys have been selected as the most suitable target materials for $1 \mathrm{D}$ nanostructures growth in the present study.

The fabrication of nanostructures of n-type bismuth telluride has been studied in great detail using a variety of different approaches including electrodeposition into porous alumina templates (4-6), surfactant-mediated solvothermal techniques $(7,8)$, step edge selective electrodeposition (9), galvanic displacement (10), high temperature organic synthesis from solution (11), low temperature and template-free synthesis (12). There are only very few reports on the preparation of p-type bismuth antimonide telluride nanostructures such as the templated electrodeposition into either anodic alumina templates (13) or polycarbonate membranes (14). The main challenge with the electrodeposition of p-type bismuth antimonide telluride nanostructures has been attributed to the low solubility of $\mathrm{Sb}$ in aqueous electrolytes which hence results in insufficient amounts of $\mathrm{Sb}^{3+}$.

Despite the success of the above mentioned methods in preparing nanostructures of $n$-and p-type bismuth telluride alloys these have clear limitations in the size and density of thermoelectric elements that can be prepared whilst not being compatible with silicon microfabrication processes. However ion-track etch lithography is a low-cost process that can product templates with deep vertical and narrow channels suitable for nanowire growth (15). It employs heavy accelerated ions as a source to damage the material, making it susceptible to chemical etching in the direction defined by the irradiation. This can produce low-cost templates for nanowire growth with diameters $<50 \mathrm{~nm}$ and high aspect ratio (> 1000).

In this paper we report the fabrication of high density arrays of n-type $\mathrm{Bi}_{2} \mathrm{Te}_{3}$ and p-type $\mathrm{Bi}_{0.5} \mathrm{Sb}_{1.5} \mathrm{Te}_{3}$ nanowires by electrodeposition into ion-track etched polyimide Kapton templates. This material offers a number of distinct advantages over porous alumina templates which include high flexibility, a low thermal conductivity $\left(0.12 \mathrm{Wm}^{-1} \mathrm{~K}^{-1}\right)$, high chemical and heat resistance (3K to 593K) and compatibility with silicon microfabrication (16) which make it promising for thermoelectric applications. In order to identify the best electrodeposition parameters for nanowire growth initial efforts focused on determining the optimal parameters for thin film deposition of $\mathrm{Bi}_{2} \mathrm{Te}_{3}$ and $\mathrm{Bi}_{0.5} \mathrm{Sb}_{1.5} \mathrm{Te}_{3}$ which were used as a starting point.

\section{Experimental details}

The polyimide samples used are based on Kapton foils with a nominal thickness of $20 \mu \mathrm{m}$ (Dupont) which are irradiated by heavy accelerated $\mathrm{Pb}^{+}$ions (4 MeV/A energy) producing the required parallel tracks with an ion-track density of $5 \times 10^{9}$ ions $/ \mathrm{cm}^{2}$. These 
are subsequently pre-etched in $\mathrm{H}_{2} \mathrm{O}_{2}$ solution at $60^{\circ} \mathrm{C}$ for 100 min followed by etching in sodium hypochlorite ( $\mathrm{NaClO}, 13 \%, \mathrm{pH} 12.5$ ) solution at $60^{\circ} \mathrm{C}$ for $2.5 \mathrm{~min}$.

Electrochemical deposition experiments were carried out in a three electrode cell using an Autolab potentiostat/galvanostat under potentiostatic control. A large area platinum gauze and saturated calomel electrode (SCE) served as counter and reference electrodes respectively. The working electrodes for $\mathrm{Bi}_{2} \mathrm{Te}_{3}$ and $\mathrm{Bi}_{0.5} \mathrm{Sb}_{1.5} \mathrm{Te}_{3}$ nanowire deposition were etched polyimide templates with an evaporated $\mathrm{Cr} / \mathrm{Au}$ seed layer attached onto a sticky copper tape. Working electrodes for thin film growth of $\mathrm{Bi}_{2} \mathrm{Te}_{3}$ and $\mathrm{Bi}_{0.5} \mathrm{Sb}_{1.5} \mathrm{Te}_{3}$ were prepared by evaporating $200 \mathrm{~nm}$ thick gold layer onto $15 \mathrm{~nm}$ Cr coated glass slides. The electrolyte solution was composed of $0.0075 \mathrm{M} \mathrm{Bi}^{3+}$ and $0.01 \mathrm{M} \mathrm{HTeO}_{2}{ }^{+}$dissolved in $1 \mathrm{M} \mathrm{HNO} 3$ with a $\mathrm{pH}$ of 0.03 . Thin films and nanowires of $\mathrm{Bi}_{0.5} \mathrm{Sb}_{1.5} \mathrm{Te}_{3}$ were prepared from electrolyte solutions containing $0.001 \mathrm{M} \mathrm{Bi}^{3+}, 0.01 \mathrm{M} \mathrm{HTeO}_{2}^{+}, 1 \mathrm{M} \mathrm{HNO}_{3}, 0.02 \mathrm{M}$ $\mathrm{Sb}^{3+}, 0.1 \mathrm{M} \mathrm{H}_{3} \mathrm{Cit}$ and $0.05 \mathrm{M} \mathrm{Na}_{3} \mathrm{Cit}$.

\section{Results and Discussion}

Fig.1 shows a representative SEM image for the etched polymer morphology of a Kapton foil that was employed for nanowire growth which was observed using a JSM-6500F scanning electron microscope (SEM). The diameter of the pores etched as a function of temperature, $\mathrm{pH}$, pre-etch conditions was on average $80 \mathrm{~nm}$ which results in a pore aspect ratios of 300:1. Through careful control of these parameters pore diameters below $20 \mathrm{~nm}$ could be achieved (17) which demonstrates the feasibility of ion-track etch technology to achieve even higher aspect ratios for thermoelectric applications. It was further found that the pores were etched all the way through the Kapton material.

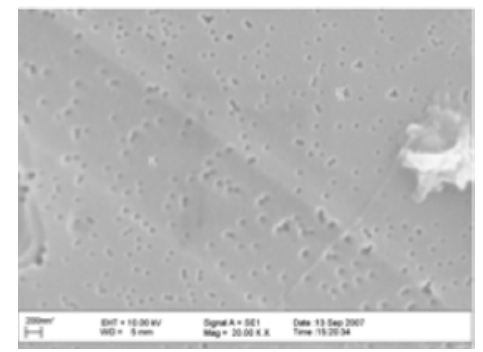

Figure.1 SEM micrograph of ion-track etched Kapton foil.

A potential of $-0.08 \mathrm{~V}$ vs. SCE yielded well adherent and stoichiometric thin films of $\mathrm{Bi}_{2} \mathrm{Te}_{3}$ and $\mathrm{Bi}_{0.5} \mathrm{Sb}_{1.5} \mathrm{Te}_{3}$ (18) and this potential was then applied to enable nanowire growth through ion-track etched Kapton templates. The surface morphology and compositions of the $\mathrm{Bi}_{2} \mathrm{Te}_{3}$ and $\mathrm{Bi}_{0.5} \mathrm{Sb}_{1.5} \mathrm{Te}_{3}$ nanowires were characterised by SEM equipped with energy dispersive X-ray (EDX) microanalysis (Oxford Inca 300) operated at $20 \mathrm{kV}$. Fig. 2 shows cross-sectional SEM images of the $\mathrm{Bi}_{2} \mathrm{Te}_{3}$ and $\mathrm{Bi}_{0.5} \mathrm{Sb}_{1.5} \mathrm{Te}_{3}$ nanowires which exhibit average diameters of $80 \mu \mathrm{m}$ with a length of $20 \mu \mathrm{m}$ and a 
density of $5 \times 10^{9}$ wires/ $\mathrm{cm}^{2}$. This is consistent with the pore size and thickness of the polyimide template. Some cleavage damage is visible in the SEM images though.
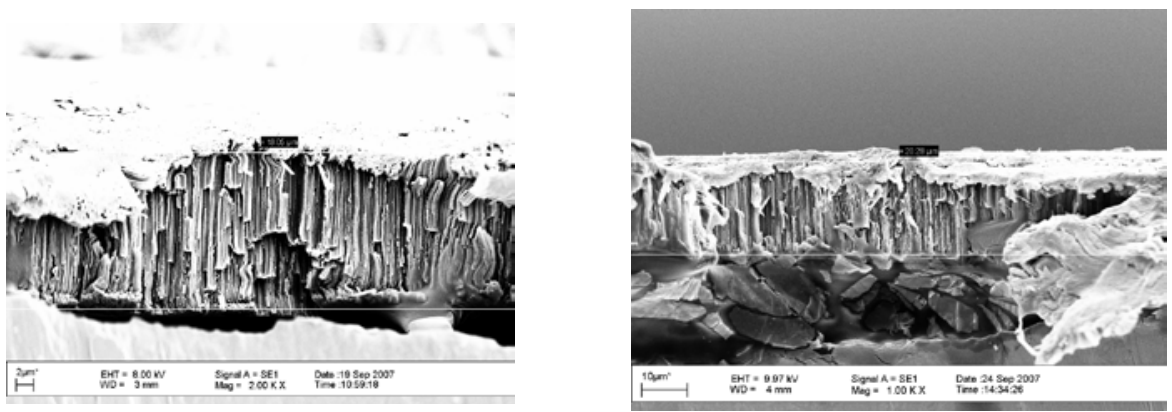

Figure 2. Cross-sectional SEM images showing electrochemical growth of $\mathrm{Bi}_{2} \mathrm{Te}_{3}$ (left) and $\mathrm{Bi}_{0.5} \mathrm{Sb}_{1.5} \mathrm{Te}_{3}$ (right) nanowires through a $20 \mu \mathrm{m}$ thick ion-track etched Kapton template. Some cleavage damage is visible.

It was feasible to liberate the nanowires by dissolution of the Kapton template in organic solvent mixtures of NMP/MEA or oxygen plasma treatment. EDX microanalysis revealed a composition of 40.95 at\% $\mathrm{Bi}$ and 59.05 at $\%$ Te for the $\mathrm{Bi}_{2} \mathrm{Te}_{3}$ nanowires and a composition of 11.26 at \% Bi, 26.23 at\% $\mathrm{Sb}$ and 62.51 at\% $\mathrm{Te}$ for the $\mathrm{Bi}_{0.5} \mathrm{Sb}_{1.5} \mathrm{Te}_{3}$ nanowires. High resolution TEM analysis performed on individual nanowires of $\mathrm{Bi}_{2} \mathrm{Te}_{3}$ in combination with selective area diffraction as shown in Fig.3 revealed a preferred growth orientation along the [110] direction with a rhombohedral space group R3m crystal structure (indexed according to ICDD PDF card 82-0358). $\mathrm{Bi}_{0.5} \mathrm{Sb}_{1.5} \mathrm{Te}_{3}$ nanowires were found to preferentially grow along the $\{110\}$ plane.

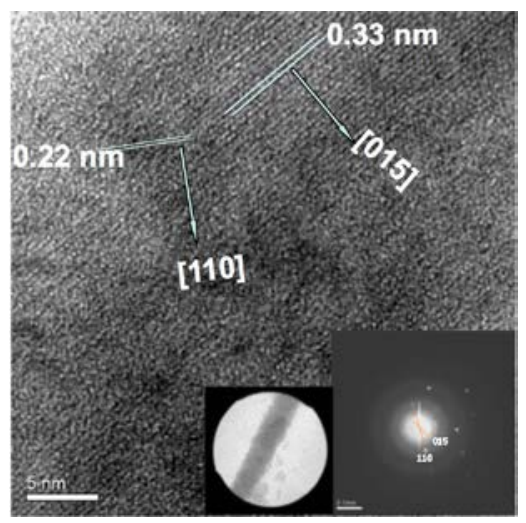

Figure 3. High resolution TEM image of individual $\mathrm{Bi}_{2} \mathrm{Te}_{3}$ nanowire. Inset: A single $\mathrm{Bi}_{2} \mathrm{Te}_{3}$ nanowire is shown at low magnification with the corresponding selective area diffraction pattern.

Transport measurements (electrical resistivity, carrier concentration, Hall coefficient and Hall mobility) were performed at room temperature in-plane on $\mathrm{Bi}_{2} \mathrm{Te}_{3}$ and $\mathrm{Bi}_{0.5} \mathrm{Sb}_{1.5} \mathrm{Te}_{3}$ 
electroplated thin films using the standard van der Pauw technique with a dc current of 19 $\mathrm{mA}$ and a permanent magnetic field of $0.55 \mathrm{~T}$ on a commercial Hall effect measuremt system (HMS300, Ecopia). To eliminate any contribution from the underlying gold substrate to the measured electrical resistivity the films were embedded in an epoxy matrix and peeled off. Ohmic contacts were made by soldering copper wires with In-Sn solder onto four corners of $1 \mathrm{~cm}^{2}$ area films and performing 10 average measurements per film to ensure reproducibility. Table 1 summarizes the results of the transport measurements for $\mathrm{Bi}_{2} \mathrm{Te}_{3}$ and $\mathrm{Bi}_{0.5} \mathrm{Sb}_{1.5} \mathrm{Te}_{3}$, thin films.

TABLE 1. Transport measurements of $\mathrm{Bi}_{2} \mathrm{Te}_{3}$ and $\mathrm{Bi}_{0.5} \mathrm{Sb}_{1.5} \mathrm{Te}_{3}$ thin films.

\begin{tabular}{|l|c|c|c|c|}
\hline Sample & $\mathrm{N} / \mathrm{p} / \mathrm{cm}^{3}$ & $\mu_{\mathrm{H}} / \mathrm{cm}^{2} \mathrm{~V}^{-1} \mathrm{~s}^{-1}$ & $\mathrm{R}_{\mathrm{H}} / \mathrm{cm}^{3} \mathrm{C}^{-1}$ & $\rho / \Omega \mathrm{cm}$ \\
\hline $\mathrm{Bi}_{0.5} \mathrm{Sb}_{1.5} \mathrm{Te}_{3}$ & $4.7 \times 10^{18}$ & 10.8 & 1.5 & 0.13 \\
\hline $\mathrm{Bi}_{2} \mathrm{Te}_{3}$ & $-6.5 \times 10^{21}$ & 29 & $-10 \times 10^{-3}$ & $3.4 \times 10^{-5}$ \\
\hline
\end{tabular}

The Seebeck coefficient was determined using a custom made Seebeck measurement unit, which was calibrated against a reference standard. The Seebeck coefficient was found to be $-52 \mu \mathrm{V} \mathrm{K}^{-1}$ for $\mathrm{Bi}_{2} \mathrm{Te}_{3}$ and $122 \mu \mathrm{V} \mathrm{K}^{-1}$ for $\mathrm{Bi}_{0.5} \mathrm{Sb}_{1.5} \mathrm{Te}_{3}$ thin films at room temperature, which is in agreement with a positive and negative Hall coefficient that $\mathrm{Bi}_{2} \mathrm{Te}_{3}$ is $\mathrm{n}$ type whereas $\mathrm{Bi}_{0.5} \mathrm{Sb}_{1.5} \mathrm{Te}_{3}$ is $\mathrm{p}$ type.

\section{Conclusions}

Ion-track etched polyimide-based Kapton foils are promising nanotemplates for the electrochemical growth of high density arrays of stoichiometric and preferentially oriented n-type $\mathrm{Bi}_{2} \mathrm{Te}_{3}$ and p-type $\mathrm{Bi}_{0.5} \mathrm{Sb}_{1.5} \mathrm{Te}_{3}$ nanowires with diameters of 20-80 nm and length of $20 \mu \mathrm{m}$ and high aspect ratios suitable for thermoelectric nanostructured generators. 


\section{Acknowledgments}

We acknowledge the Engineering and Physical Sciences Research Council fro supporting this work through grant EP/DO76250.

\section{References}

1. D.M. Rowe, Handbook of Thermoelectrics, CRC, Boca Raton (1995).

2. G. J. Snyder and E.S. Toberer, Nature Mat. 7, 105 (2008).

3. L.D. Hicks and M.S. Dresselhaus, Phys. Rev. B 47, 1272 (1993).

Formatted: English (U.K.)

4. S. A. Sapp, B. B. Lakshmi and C. R. Martin, Adv. Mater. 11, 402 (1999).

5. A. L. Prieto, M. S. Sander, M. S. Martin-Gonzalez, R. Gronsky, T. Sands and A. M. Stacy, J. Am. Chem. Soc. 123, 7160 (2001).

6. M. S. Sander, A. L. Prieto, R. Gronsky, T. Sands and A. M. Stacy, Adv. Mater. 14, 665 (2002).

7. H. Yu, P. C. Gibbons and W. E. Buhro, J. Mater. Chem., 14, 595 (2004).

8. Y. Deng, C. Cui, N. Zhang, T. Ji, Q. Yand and L. Guo, Solid State Commun.,138, 111 (2006).

9. E. J. Menke, Q. Li and R. M. Penner, Nano Lett., 4, 2009 (2004).

10. F. Xiao, B. Yoo, K. H. Lee and N. V. Myung, J. Am. Chem. Soc. 129, 10068 (2007).

11. W. Lu, Y. Ding, Y. Chen, Z. L. Wang and J. Fang, J. Am. Chem. Soc. 127, 10112 (2005).

12. A. Purkayastha, F. Lupo, S. Kim, T. Borca-Tasciuc and G. Ramanath, Adv. Mater.18, 496 (2006).

13. M. M. Gonzalez, A. L. Prieto, R. Gronsky, T. Sands and A. M. Stacy, Adv. Mater.15, 1003 (2003).

14. B. Yoo, F. Xiao, K. N. Bozhilov, J. Herman, M. A. Ryan and N. V. Myung, Adv. Mater. 19, 296 (2007).

15. C. R. Martin, Science 266, 1961 (1994).

16. M. Lindeberg and K. Hjort, Microsyst. Technol. 10, 608 (2004).

17. E. Koukharenko, X. Li, I. S. Nandhakumar, M. J. Tudor, S. P. Beeby, B. Schiedt, C. Trautmann and N. M. White, Electron. Lett, 44, 500 (2008).

18. X.Li, E Koukharenko, I.S. Nandhakumar, J.Tudor, S.P. Beeby and N.M. White, PCCP 11, 3584 (2009).

Formatted: Italian (Italy)

Formatted: German (Germany) 